\title{
Determinants Of Computer Anxiety In Business Students
}

\author{
Travis Broome, (broome@hotmail.com) Miami University
}

Douglas Havelka, (havelkdj@muohio.edu) Miami University

\begin{abstract}
An empirical study was performed to identify significant determinants of computer anxiety among business students. The results indicate that there are significant differences in computer anxiety levels among students with different academic majors, among students that have taken a different number of computer courses, and among students that have learned a different number of software applications or programming languages. The study found no significant difference in computer anxiety between male and female students, contrary to earlier studies. In fact, female students had an overall lower level of computer anxiety than did their male counterparts.
\end{abstract}

\section{Introduction}

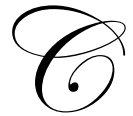

omputer anxiety has been defined as the fear of computers when using the computer, or when considering the possibility of computer use (Heinssen, et al., 1987). Research has shown that computer anxiety affects the way individuals view a specific software package and their use of that software (Venkatesh, 2000). In fact, prior studies have shown that higher levels of computer anxiety are correlated with lower students' grades in the social sciences when those students are asked to use computers to perform certain tasks (Bowers and Bowers, 1996). There is also evidence that computer anxiety impacts the perceived benefit of using a computer (Bozionelos, 1997b) and the user's computer competence (Bradley and Russell, 1997).

Studies also suggest a discrepancy in computer anxiety levels among different demographic sectors, most prevalently between men and women. A survey of computer anxiety levels in men and women undergraduate students since 1992 shows that while male levels of anxiety have decreased, those in women have remained fairly consistent (Todman, 2000). This suggests that current technology could possess a gender bias that imposes a barrier to women in the workplace, limiting their potential for advancement.

It appears likely that students studying information systems and computer sciences will possess the lowest levels of computer anxiety due to their experience with technology and their interest in using technology. However, some have suggested that individuals that work with technology regularly will display higher levels of computer anxiety, because they must work with technology more often (Towell and Lauer, 2001). There is evidence that computer experience is the most consistent correlate in the measurement of the degree of anxiety experienced by microcomputer users (Chu and Spires, 1991).

Other determinants of computer anxiety have been investigated. Earlier research has also indicated that computer anxiety is associated with different types of learning styles (Bozionelos, 1997a). This may suggest that students with different learning styles may require different types of training or human-computer interfaces to reduce computer anxiety and thereby increase their performance. Some research has been performed to discern differences in computer anxiety between various dissimilar nations (Rosen and Weil, 1995). They found definite, measurable differences based on the culture of the society in which the technology resides. Research has shown that even among individuals who may share similar cultural upbringings, factors such as gender and background experience may play a role (McIlroy, et al., 2001). 
Given these findings and the prevalence of computers in society today, it is useful to further investigate the determinants to computer anxiety among individuals. Most research indicates that computer anxiety is not an inherent emotion but rather a "state anxiety" that can be treated (Chu and Spires, 1991). By identifying the determinants to computer anxiety; researchers, managers, educators, and trainers may be better able to structure learning and training experiences to minimize the deleterious effects of computer anxiety. Therefore it is the objective of this research to identify determinants of computer anxiety among a select population, i.e. business school students.

In the next section, several hypotheses are generated related to the potential determinants of computer anxiety for business students.

\section{Hypotheses Development}

Some researchers have identified differences in levels of computer anxiety among students from different populations (Burkett, et al., 2001) and among students with different personality types (Towell and Lauer, 2001). These findings suggest that students with different levels of computer anxiety may perform differently when asked to use computers to perform a task. Therefore, it is important to determine if differences among students within different disciplines exist. By doing so, prescriptive actions could be taken by administrators or faculty to reduce computer anxiety among the groups that would most benefit from such action. Based on the results of prior research and the objectives of this study the first hypothesis is stated, in alternative form, for testing as:

H1: There are differences in computer anxiety among students with different academic majors.

Just as previous research tends to indicate differences in computer anxiety levels across dividing lines such as nationality (Rosen and Weil, 1995) and that of gender (Todman, 2000) exist, this study will determine whether students within different academic disciplines within the business school also display discrepancies.

Computer experience has been shown to reduce computer anxiety levels (Chu and Spires, 1991). To further investigate the relationship between computer experience and computer anxiety levels, several hypotheses are proposed. First, it would be expected that students who have more years of experience using a computer would have lower levels of computer anxiety. Therefore, the following hypothesis is given:

H2: There are differences in computer anxiety among students with different years of experience using a computer.

In addition to the number of years of experience using a computer, the number of courses that students have taken would also be expected to influence computer anxiety levels. This should also give some indication as to whether additional coursework should be required to mediate the effects of computer anxiety. Therefore, hypothesis three is stated as:

H3: There are differences in computer anxiety between students with different amounts of computer coursework.

An additional measure of computer experience is the number of applications, software packages, or programming languages a student has used. It would be expected that as the number of different programs that a student uses increases, their level of computer anxiety would decrease. Hypothesis four is stated as:

H4: There are differences in computer anxiety between students that have used different numbers of software applications.

As mentioned in the introduction, almost all career choices made in today's business environment require at least a modicum of skill in using information technology. For this reason, the results of this study should reveal whether exposing students to different types of software or technology would help to reduce computer anxiety. 
Previous research has shown differences in computer anxiety between men and women and among students of different nationalities (Rosen and Weil, 1995; Todman, 2000). Previous research has pointed out the negative consequences of differences in computer anxiety for men and women and the relevancy of gender in determining levels of computer anxiety (McIlroy, et al., 2001; Todman, 2000). These studies suggest that women may be at a disadvantage in the workplace where the use of computer technology is involved. To validate the findings of the previous research and to determine if any changes have occurred, a hypothesis related to gender is tested:

H5: There are differences in the level of computer anxiety levels between male and female students.

To address these hypotheses an empirical study was performed. The survey and methods used are discussed in the next section.

\section{Research Design \& Data Collection}

A survey instrument was used to collect data to test the hypotheses. The instrument used to collect the data is based on the Computer Anxiety Rating Scale (CARS) developed by Heinssen et al. (Heinssen, et al., 1987) and validated by $\mathrm{Chu}$ and Spires (Chu and Spires, 1991). Since its development the instrument has been updated and administered to thousands of university students, schoolteachers, secondary school students and business people throughout the United States and university students in 22 other countries (Bradley and Russell, 1997; Rosen and Weil, 1995; Weil and Rosen, 1995). It has also played an integral part in research into the structure of computer anxiety (McIlroy, et al., 2001). The discriminatory capabilities of the CARS survey has been praised in research conducted regarding predictors of computer anxiety and performance in information systems (Anderson, 1996). Researchers continue to use the latest revision of the survey in inquiries into computer anxiety across varied cultures (Rosen and Weil, 1995).

The CARS survey's high reliability in measuring computer anxiety stems from its format of a series of questions designed specifically to measure an individual's apprehension toward computers. The CARS instrument is a 19-item, five-point self-rating scale used to assess the subject's computer anxiety level and is presented in Appendix A. The original instrument was modified to update the item descriptions for changes in technology since 1987 and an additional scale item added based on suggestions from prior researchers (Rosen and Weil, 1995). Students responded to a series of statements, such as "Getting Error Messages From a Computer," based on how anxious the statements made them feel (from $1=$ Not at All to $5=$ Very Much). The section of questionnaire designed to measure computer anxiety levels consists of twenty questions, ten of which are reverse coded. A score of 100 would indicate the highest level of anxiety possible and a score of twenty would be the low. With a maximum score of 100 , ratings in excess of 70 were considered to possess moderate to severe anxiousness when confronted with a task involving computer related work.

This instrument was administered to students enrolled in summer business courses at a large Midwestern University. A total of 172 completed surveys were collected from eight separate classes. The classes included courses from different business disciplines, i.e. marketing, accounting, finance, and MIS, as well as different grade levels, i.e. freshman. The breakdown of the respondents with reference to their declared majors is given in Table 1. The respondents were composed of 100 men and 72 women. There were 11 graduate students, 12 sophomores, 38 juniors, and 72 seniors. There were no freshmen in the summer courses.

$\begin{array}{lc}\text { Major } & \frac{\mathbf{N}}{36} \\ \text { Accounting } & 45 \\ \text { Finance } & 11 \\ \text { Management } & 19 \\ \text { Marketing } & 47 \\ \text { MIS } & 14 \\ \text { Other } & 172 \\ \text { Total } & \end{array}$

Table 1 - Breakdown of Respondents by Major 


\section{Data Analysis \& Results}

Each of the hypotheses presented were tested using a one-way analysis of variance. Hypothesis 1, that there are differences in computer anxiety levels among students with different academic majors, is significant at the 0.000 level. The ANOVA results are presented in Table 2 .

\section{Table 2 - ANOVA for Computer Anxiety Levels by Major}

$\begin{array}{lccccc}\text { Source } & \frac{\mathbf{d f}}{5} & \frac{\mathbf{S S}}{172} & \frac{\mathbf{M S}}{634} & \underline{\mathbf{F}} & \mathbf{\underline { \mathbf { P } }} \\ \text { Major } & 166 & 21246 & 128 & \\ \text { Error } & 171 & 24418 & & \\ \text { Total } & \underline{\mathbf{N}} & \underline{\mathbf{M e a n}} & \underline{\mathbf{S d e v}} & \\ \mathbf{\text { Groups }} & 36 & 37.56 & 9.53 & \\ \text { ACC } & 45 & 41.80 & 10.55 & \\ \text { FIN } & 11 & 43.18 & 7.35 & \\ \text { MAN } & 19 & 44.37 & 16.76 & \\ \text { MAR } & 47 & 32.70 & 12.06 & \\ \text { MIS } & 14 & 42.21 & 8.29 & \end{array}$

With a p-value of 0.000 , it is safe to assume that at least two of the means of the disciplines considered are different. This is consistent with the assumption that those students in fields heavily reliant upon technology would have a higher degree of confidence and lower anxiety when dealing with computing technology. Fisher's pairwise comparisons (at $\mathrm{p}=.05$ level) reveals that significant differences exist between the MIS group and finance, MIS and management, MIS and marketing, and MIS and other majors. There is also a significant difference between accounting and marketing. This result suggests that there are differences in computer anxiety levels among the various business disciplines. Overall, it appears that MIS and accounting majors have the least amount of computer anxiety and that marketing and management majors tend to have higher levels of anxiety (it appears that finance and other majors fall in the middle).

The results associated with Hypotheses 2, there are differences in computer anxiety levels among students with different years of experience using a computer were not significant. The question used to gather this data used ranges to identify the number of years of experience $(\mathrm{a}=0, \mathrm{~b}<1, \mathrm{c}=1-2, \mathrm{~d}=2-5$, e $>5$ years). The data collected show that 157 out of the 172 students had greater than five years experience using a computer. This seems to imply that the number of years that a student has used a computer is not a good indicator of their level of experience. Or at least not a good indicator of experience as it affects computer anxiety.

Hypothesis 3 , that there is a difference in computer anxiety due to the number of computer courses taken, is significant at the $\mathrm{p}<0.002$ level. Table 3 presents the ANOVA results for computer anxiety by the number of computer courses taken. It should be noted that out of the 172 students none indicated that they had taken zero courses. Fisher's pairwise comparisons reveal that there were significant differences (at the .05 level) between those with greater than three courses and all of the other groups. Surprisingly, it appears that the largest difference occurs between the three-courses group and the greater-than-three group. It may be that there is a threshold effect, i.e. that once a student gets past that third course their anxiety level falls off dramatically. 


$\begin{array}{lccc}\text { Source } & \frac{\mathbf{d f}}{3} & \underline{\mathbf{S S}} & \underline{\mathbf{M S}} \\ \text { Courses } & 168 & 22382 & 679 \\ \text { Error } & 171 & 24418 & 133 \\ \text { Total } & \underline{\mathbf{N}} & \underline{\text { Mean }} & \\ & \underline{4} & \underline{\mathbf{S d e v}} \\ \mathbf{\text { Groups }} & 31 & 41.35 & 8.07 \\ 1 & 31 & 43.71 & 9.41 \\ 2 & 95 & 35.8 & 15.77 \\ 3 & & & 10.99\end{array}$

In addition, these results reveal an interesting trend relating coursework to anxiety. It appears that computer anxiety levels remained fairly consistent until the third course when it actually increased before taking a drastic drop after the third course completed. This could very well be a result of the increase in difficulty associated with higherlevel computer science and MIS offerings. While a student may feel comfortable working with common software applications, the idea of studying the details of computer infrastructure and the requirement of coding their own applications may actually hinder their confidence until they overcome those fears, at which point their greatly increased understanding of the human-machine interface allows for a higher degree of confidence and a much lower level of computer anxiety.

Hypothesis 4, that there is a difference in computer anxiety among students that have learned a different number of applications, software packages, or programming languages, is also significant ( $\mathrm{p} 0.007)$. The ANOVA results are given in Table 4.

Table 4 - ANOVA for Computer Anxiety Levels by Number of Different Applications Learned

$\begin{array}{lccccc}\underline{\text { Source }} & \underline{\mathbf{d f}} & \underline{\mathbf{S S}} & \underline{\mathbf{M S}} & \underline{\mathbf{F}} & \underline{\mathbf{P}} \\ \text { Number } & 167 & 22433 & 134 & \\ \text { Error } & 171 & 24418 & & \\ \text { Total } & \frac{\mathbf{N}}{7} & \underline{\mathbf{M e a n}} & \underline{\mathbf{S d e v}} & \\ \underline{\text { Groups }} & 15 & 45.43 & 9.00 & \\ 0 & 12 & 46.40 & 16.50 & \\ 1 & 12 & 42.58 & 9.95 & \\ 2 & 126 & 36.86 & 10.29 & \\ 3 & & 11.27 & \end{array}$

Similar to the number of courses taken, it appears that as the number of different applications a student learns increases their level of computer anxiety goes down. Fisher's pairwise comparisons reveals only one significantly different pair between those students that have learned only one application and those that have learned greater than three applications. This result also indicates that there appears to be more than a simple linear relationship between computer anxiety and experience with technology. It appears that there may be an increase in the level of computer anxiety as students begin to learn technology and that the student then "pushes on through" by taking more courses or learning more applications with the effect of lowering their computer anxiety level, or alternatively they choose not to learn more and remain at an uncomfortable computer anxiety level. Certainly these are propositions that would need to be addressed by further research and are not proven or disproven here.

Hypothesis 5, that there are differences in the level of computer anxiety between male and female students, was not found to be significant. Table 5 gives the ANOVA results. 
Table 5 - ANOVA for Computer Anxiety Levels by Gender

\begin{tabular}{lccccc} 
Source & $\frac{\mathbf{d f}}{1}$ & $\underline{\mathbf{S S}}$ & $\underline{\mathbf{M S}}$ & $\underline{\mathbf{F}}$ & $\mathbf{\underline { \mathbf { P } }}$ \\
Gender & 170 & 23931 & 141 & \\
Error & 171 & 24418 & & \\
Total & $\underline{\mathbf{N}}$ & $\underline{\mathbf{M e a n}}$ & $\underline{\mathbf{S d e v}}$ & \\
$\mathbf{\text { Groups }}$ & 100 & 40.26 & 13.35 & \\
\hline Male & 72 & 36.85 & 9.42 &
\end{tabular}

However, the results are interesting for at least two reasons. One, the fact that prior research consistently found that male students had significantly lower computer anxiety and no significant difference was found may indicate that female students have "caught up" to their male counterparts with regard to technology. And two, although the difference was not significant $(\mathrm{p}<0.064)$, the fact that the mean value for computer anxiety for the men was higher than the women is interesting. The researchers feel that this statistically unsupported difference translates into a significant real-world implication of a shift in the traditionally gender-biased roles in the world of business with regard to technology.

\section{Conclusion}

This study should be of interest to researchers, university administrators, educators, and to the business community and society in general. The results indicate that there are significant differences in computer anxiety among business students with different majors, that have taken a different number of computer courses, and that have learned a different number of software applications. This study found no evidence that the number of years of computer experience, as measured by the number of years of computer usage, had an influence on computer anxiety. Also, the study found no evidence to support the gender-based differences in computer anxiety found by earlier research. In fact, there appears to be some evidence that female students have lower levels of computer anxiety than male students. For university administrators, the results will show which areas may benefit from additional computer training or other forms of "intervention" to prepare students for life in technological society. For educators, the results will provide some direction in using technology, i.e. they may wish to adjust their assumptions regarding the use of technology in the classroom. Lastly, for the business community and society at large, the results imply ways for reducing the negative effects related to computer anxiety.

\section{Suggestions for Future Research}

The results of this study suggest several avenues for further research. First, specific interventions to reduce computer anxiety should be investigated, especially for those groups that would be more likely to have high levels of computer anxiety. Second, this study found no significant differences between male and female students' computer anxiety. Future work should be performed to determine whether this is a substantive change or perhaps is limited to students in business majors. Third, a similar study should be performed to identify other professions that may have high levels of computer anxiety that impede productivity when working with technology. Lastly, the relationship between computer anxiety and other psychological constructs of interest, user involvement or user satisfaction, should be pursued.

\section{References}

1. $\quad$ Anderson, A.A. "Predictors of Computer Anxiety and Performance in Information Systems," Computers in Human Behavior (12:1), 1996, pp. 61-77.

2. Bowers, D.A.J. and Bowers, V.M. "Assessing and coping with computer anxiety in the social science classroom.," Social Science Review (14:4), 1996, pp. 439-443.

3. Bozionelos, N. "Psychology of computer use: XLIV computer anxiety and learning style.," Perceptual and 
Motor Skills (78), 1997a, pp. 753-754.

4. Bozionelos, N. "Psychology of computer use: XLV. Cognitive spontaneity as a correlate of computer anxiety and attitudes toward computer use," Psychological Reports (80), 1997b, pp. 395-402.

5. Bradley, G. and Russell, G. "Computer experience, school support, and computer anxiety," Educational Psychology (17:3), 1997, pp. 25-28.

6. Burkett, W.H., Compton, D.M. and Burkett, G.G. "An examination of computer attitudes, anxieties, and aversions among diverse college populations: Issues central to understanding information sciences in the new millennium," Informing Science (4:3), 2001, pp. 77-85.

7. Chu, P.C. and Spires, E.E. "Validating the computer anxiety rating scale: Effects of cognitive style and computer courses on computer anxiety," Computers in Human Behavior (7:1/2), 1991, pp. 7-21.

8. Heinssen, R.K.J., Glass, C.R. and Knight, L.A. "Assessing computer anxiety: Development and validation of the computer anxiety rating scale," Computers in Human Behavior (3:1), 1987, pp. 49-59.

9. McIlroy, D., Bunting, B., Tierney, K. and Gordon, M. "The relation of gender and background experience to self-reported computing anxieties and cognitions," Computers in Human Behavior (17), 2001, pp. 21-33.

10. Rosen, L.D. and Weil, M.M. "Computer Anxiety: A Cross-Cultural Comparison of University Students in Ten Countries," Computers in Human Behavior (11:1), 1995, pp. 45-64.

11. Todman, J. "Gender Differences in Computer Anxiety Among University Entrants Since 1992," Computers \& Education (34), 2000, pp. 27-35.

12. Towell, E.R. and Lauer, J. "Personality differences and computer related stress in business students," MidAmerican Journal of Business (16:1), 2001, pp. 69-75.

13. Venkatesh, V. "Determinants of perceived ease of use: Integrating control, intrinsic motivation, and emotion into the technology acceptance model," Information Systems Research (11:4), 2000, pp. 342-365.

14. Weil, M.M. and Rosen, L.D. "The Psychological Impact of Technology From a Global Perspective: A Study of Technological Sophistication and Technophobia in University Students From Twenty-Three Countries," Computers in Human Behavior (11:1), 1995, pp. 95-133.

\section{Appendix A - Modified Computer Anxiety Rating Scale}

- I feel insecure about my ability to interpret and use a new computer application.

- I look forward to using a computer on my job.

- $\quad$ I do not think I would be able to learn a computer programming language.

- $\quad$ I am confident I can learn computer skills.

- $\quad$ Anyone can learn to use a computer if they are patient and motivated.

- $\quad$ Learning to operate a computer is like learning any new skill --- the more you practice the better you become.

- I I am afraid that if I begin to use computers I will become dependent on them and lose some of my reasoning skills.

- $\quad$ I am sure that with time and practice I will be as comfortable working with computers as I am working with basic word processing software.

- $\quad$ I feel that I will be able to keep up with the advances happening in the computer field.

- I dislike working with machines that are smarter than I am.

- I I feel apprehensive about using computers.

- I have difficulty in understanding how a computer works.

- It scares me to think that I could cause the computer to destroy a large amount of information by hitting the wrong key.

- I hesitate to use a computer for fear of making mistakes that I cannot correct.

- You have to be a genius to understand all the special commands contained in most computer software.

- If given the opportunity I would like to learn about and use computers.

- I I have avoided computers because they are unfamiliar and somewhat intimidating to me.

- I feel computers are necessary tools in both educational and work settings.

- $\quad$ The challenge of learning computers is exciting. 
- I feel that understanding computers will make me a more productive individual.

Notes 